\title{
Why psychosocial thinking is critical
}

The title of this chapter is really a statement, with a question inscribed in it, and a double meaning at its heart. It seeks to both answer 'why is psychosocial theory critical?' and argue that psychosocial theory is critical, in the sense of challenging orthodoxy, and in the sense of urgent and necessity. The short answer that will be advanced here is this: without engaging with people as subject to unequal forms of social power, interwoven with individual, affective struggles and troubles, you cannot hope to understand the complexities of human existence, let alone human existence in which some people are clearly experiencing forms of social suffering.

Psychosocial thinking insists that humans are understood as being constituted within social structures and personal internal landscapes. However, there is also a third fundamental element, which is that the experiencing, relational human subject is placed at the centre of the analysis. The knower and the known in terms of knowledge construction; the worker and the service user in social work, are both equally dynamically present and constitutive in all encounters, and this subjective interface is fundamental to the relationship. The human subject is at the core of psychosocial understanding. As I have commented previously:

Within this paradigm the subject is understood as passionate, ambivalent and emotionally driven, existing outside (but defined within) the rational processes of language. Importantly, this is a social subject existing in a world of power relations and status hierarchies. Psychosocial theory is able to explicate the emotional experience which, in relation to all encounters, including social work, defines the nature of the real and fantasised self and other in a coconstructed relationship.

(Frost, 2008: 4)

Many theories, of course, have claimed to dissolve the structure versus agency binary, or at the least consider how individuals are both stitched into social worlds, but maintain some elements of free will. We could for example think of symbolic interactionists such as Goffman (1959) or Giddens (1984). Or poststructuralists such as Foucault (1977). Psychosocial studies builds on this tradition, arguing that individuals are both the product of social forces and of their specific psychic worlds, and that these are mutually constitutive. The picture is dynamic, the forces inseparable. How one is able to see the 'external' world is impacted on by one's dynamic

Taylor and Francis Not for distribution Liz Frost 116 
psychological make-up: how one's inner life can pan out is impacted on by the 'external' forces of, for example, power within social hierarchies. As Hollway and Jefferson neatly summarise:

Subjects whose inner worlds cannot be understood without knowledge of their experiences in the world, and whose experiences of the world cannot be understood without knowledge of the way in which their inner worlds allow them to experience the outer world.

The quick answer to why psychosocial thinking is critical is, then, that it offers a 'rich' version of human esperience in a constant and constituting relationship with their 'environment' in the broadest sense, and as conflictual, bruised, affective, struggling, changing - and that applies to social workers, service users, and indeed everyone else.

Having introduced some ideas in relation to what psychosocial thinking is, this chapter will now go on to briefly discuss its, somewhat confusing, terminology, background and contemporary context. It will then consider some of the impact of psychosocial thought in education and knowledge building for social work, and finally focus on the situation of the 'social work self' in relation to the service user. Of what use this is to social work and social workers is addressed through examples in both these areas.

Social work theory, particularly critical theory, has always been wary of any form of thought with 'psych' in the title, and in many ways the nomenclature does the concept no favours. This is discussed at length in earlier papers (Frost, 2008,2015 ) and will not be revisited in such detail here. However, it might be useful to understand a little of the history and current dynamic emergence of contemporary psychosocial studies. This use of 'psychosocial' emanates primarily from sociology and critical psychology, in the last two decades, and insists that social structural theory and psychoanalysis are core components. The Association for Psychosocial Studies website provides a useful definition: http://www.psychosocial-studies-association.org/about/

There are also a small number of psychosocial theorists who argue that critical depth psychology can stand in for psychoanalysis (see Brown and Stenner, 2009).

But 'psychosocial' is also used as term in positivist psychology, child psychology and psychotherapy, and related disciplines, and usually has a meaning nearer 'individual psychology in the context of familial relations' (e.g. Rutter, 1999). This has a longer history but is more limited in scope. Equally, in social work, psychosocial is often interchangeably used with the slippery concept of 'psychodynamic', which also tends to mean 'a person in context', but usually with little reference to either hierarchical power or psychoanalytic theory. In some versions a link to Freudian concepts is claimed (e.g. Payne, 2015), but this is by no means always evident, or rigorous. Usually it means something loosely social and psychological (Frost, 2008). There is then an ongoing, fluid, reformulation, driven mainly from sociology, of psychosocial theory, and within this discipline this is new, exciting and possible. Translated to social work however the term itself comes with 'baggage' to confront. Suspicion of its clinical past, and the 'radical' critique this occasioned, has never quite disappeared. For some, the mere mention of 'psych' seems to induce a myopic refusal to hear the 'soc'.

Contemporary psychosocial theory draws on a tradition of Continental Critical Theory, and particularly from the Frankfurt School, which utilised Marxism and psychoanalysis to understand the cataclysmic violence and upheaval of war-torn Europe in the twentieth century (Clarke, 2005; Gadd and Dixon, 2010). Fromm, Marcuse and Adorno, for example, developed theoretical frameworks concerned with amalgamating understandings of the external, political world and the internal worlds of individuals. Added to this their insistence that their work should challenge the notion of objectivity and adhere to principles of social relevance

Taylor and Francis Not for distribution Why psychosocial thinking is critical 117 
and committed application, sets in place the trajectory in which psychosocial theorists locate themselves. In this sense psychosocial theory inherits, and is defined by, 'the critical', though often contemporary critical theorists overlook the founding principles of psychoanalytical thought intrinsic to this movement.

These last-century modernists' fundamental concerns were with social justice, liberation, truth, repression, hatred, endurance and the nature of humans forged in and forging this morass. And these are still, one could argue, the ethical concerns at the heart of social work. However it is worth acknowledging that in the wake of the later twentieth century's sociological concerns with identity and also with the linguistic construction of subjectivities, and other tenets of poststructuralism, the sociologists and psychoanalysts drawn on currently to construct psychosocial theory are as likely to be Bourdieu with Klein (Frost and Hoggett, 2008), Honneth with Winnicott (Houston, 2010) or Guattari with Lacan (Walkerdine, 2014) as Marx and Freud.

Given its roots in forms of psychology, political science, philosophy and sociology, it is perhaps unsurprising that a distinctive and defining element of 'new' psychosocial theory is its multi-disciplinarity. It is also important that the boundaries being blurred are not just those associated with the academy, but, perhaps because of its unique relationship to the human-centred in its discourses, those of theory and practice. Although much psychosocial theory is being driven by intersecting disciplines of social policy, sociology and (critical) psychology, some of its leading scholars have histories of public engagement and 'welfare' employment. Key innovators in psychosocial thinking, for example, Paul Hoggett, came to academia from backgrounds of political activism, and 'growing' their knowledge base through training as psychotherapists and/or psychoanalysts as well as their practices as academics (Hoggett, 2014). Similarly, some practitioners in areas such as mental health, whether qualified as social workers, psychologists or therapists, bought this experiential sensibility into the world of theory when they moved into the academy (Frosh, 2014).

The ongoing project of developing psychosocial theory is largely in opposition to the traditional delimitation of disciplinary silos in the academy and insists on blurring boundaries and distinctions: another area of criticality. This has also encompassed challenging some unhelpful and misleading dichotomies on the way: for example, agency or determinism; practice or theory; sociology or psychology; the internal or the external; the knower or the known. The 'project' overall is to develop a multi-layered, complex and rich version of the human subject in context, not by cherry picking random ideas from various disciplines, but by developing a coherent body of critical theory: a broad lens through which to observe, understand, and indeed positively intervene in the contemporary world. This is also a discipline (reflecting the subject of its engagement) which has an identity in formation: a process, not a product. Its boundaries and scope are still flexible, and definitions not yet solidified.

Thinking now specifically about theory for social work, 'new' psychosocial theory began to emerge about two decades ago, and in relation to social policy, with texts such as Love, Hate and Welfare (Froggett, 2002) and Borderline Welfare: Feeling and Fear of Feeling in Modern Welfare (Cooper and Lousada, 2005) querying the assumption of 'rational' subjects and 'rational' processes, and insisting that relational and defensive elements of punitive policy making be named and challenged. A gradual incursion of psychosocial thinking in social work practice situations occurred over the next decade, for example, in child protection, and working with young people (Ferguson, 2005; Briggs, 2008) as well as texts concerned with understanding social structural inequality as the underpinning basis of service users' struggles (e.g. Frost and Hoggett, 2008; Gadd and Dixon, 2010; Scanlon and Adlam, 2013; Hadar, 2013). In the last few years both the applied methodology developments of relationship-based practice have drawn on psychosocial paradigms (Trevithick, 2003; Ruch et al., 2010; Froggett et al., 2015) and emerging theoretical

Taylor and Francis Not for distribution Liz Frost 118 
work on, for example, recognition and shame have been examined through a psychosocial lens in the context of social work and social justice (e.g. Gibson, 2015; Houston, 2016; Frost, 2015).

And much of this work is critical. Psychosocial thinking is critical of old ways of understanding and traditional ways of practising. It is critical of the state, of policy and political decisions, of sexism and racism, of a failure to understand the depth of damage caused by 'rational' decision making. It argues, for example, that political decisions lead to severely damaged psyches. Poverty, and the callous contemporary benefits systems which instigates and reinforces this, certainly limits opportunities, guarantees substandard living, and endless hardship. However, it also engenders shame, anxiety, and a sense of worthlessness. No one should have to feel shamed for what is outside their control, but research and practice understands that people do: a core point that perhaps those who have never lived within subaltern identities find it hard to relate to. Even classic studies such as Sennett and Cobb's The Hidden Injuries of Class (1973), argued 40 years ago that the working-class men they studied, men who had been systematically damaged by structural class inequalities, also blamed themselves. They experienced deep discomfort that permeated their identities and capacity to move positively in the world (see below). We also know from research that within contexts of gender oppression girls who were sexually abused and women who were raped frequently internalise this as somehow their fault, and too shaming to speak of (Feiring and Taska, 2005).

To understand that 'political damage' is internalised and suffered at an individual, isolating and pervasive level (feeling shame, for example, can isolate and silence individuals from/in the world, Nussbaum, 2004) is not to deny the political, but to enhance understanding of how devastating, powerful and deeply personal the political really is. However, as this chapter argues, psychosocial thinking is also critical in the sense of fundamentally important for social work. All of the above implies this, but the next section of this chapter will specifically develop this theme, in relation to teaching and learning.

Undergraduate and post-graduate social work students at the university where I work have, for several years now, undertaken a social science curriculum which contains what can be thought of as fairly mainstream sociology. Their understanding of the world is examined and enhanced through drawing on theorists such as Foucault, Hochschild, Giddens, Burman and Bourdieu, with additional material from social psychologists and philosophers such as Goffman and Honneth.

Sociological concepts of, for example, social constructionism, power, agency, identity, risk, resilience, emotional labour and cultural capital, are necessary, we suggest, for understanding the social work subject. However, this in itself is not sufficient. To understand how, for example, 'symbolic violence' or 'social suffering' (Bourdieu, 1973, 1999) are actually experienced, and are constitutive of identity, needs, we believe, theories of the mind: of the internal world of the human into which such experience becomes integrated.

As I have argued previously (Frost, 2015) it is only really when sociology is matched with psychoanalytical theory (e.g. from Klein, Winnicott, Bowlby, and Lacan) that the specifically social work oriented social science curriculum one in which practice can be elucidated - makes sense. Psychoanalytic ideas, which would include defences and desire, hatred and 'ressentiment', anxiety, containment, and desire, identification, attachment (Frosh, 2012; Hoggett et al., 2013) are important to even begin to make sense of the complexities and potential of not just processes such as early childhood development but the actual relational social work encounter itself. Psychosocial thinking enables a learning environment fit for the task in hand: helping potential social workers understand the context and specifics of their chosen field of practice. Jan Fook made the oft repeated observation of being taught sociology as a trainee social worker. Describing her experience of social work academia, she comments:

\section{Taylor and Francis Not for distribution Why psychosocial thinking is critical 119}


What I found was ... a world in which it seemed that male academic theorising sociologists tried to teach female practising social workers better social work by converting them to a world of theory (e.g. Althusser).

(Pease and Fook, 1999: 5)

This is more a question of 'what world (s) of theory' rather than theory - even structural theory - per se. The psychosocially oriented curriculum, locating the individual experience as the centre of focus, aligns theoretical thinking with practice, in a general and specific sense. What would it help these developing social workers to understand more about, and through what theory? Theming teaching into 'life stages' and intersectional themes (e.g. youth and transitions; ageing and ageism; recognition and shame; loss and grieving), rather than by 'key thinkers' or typographies of theory reflect this. To consider recognition one might draw on feminist political theorist Nancy Fraser, philosopher Axel Honneth, and psychoanalytical theorist Donald Winnicott. To consider ageism, body sociology theorists are helpful, but also philosopher Simone de Beauvoir (1970) and psychoanalyst Melanie Klein (for all forms of 'othering'). Youth and transition ranges across sociologists such as Bourdieu (1973), but also psychosocial theorists Jimenez and Walkerdine studying the formation of young masculine identities and shame in post-industrial contexts (2011).

In each case work from psychosocial theory allows an integration of ideas, whilst putting the subject at the centre of the work. Practice issues are under-pinned by these interwoven, psychosocial notions. Shame and recognition, young people in transition and ageism/ageing are core to many social work practice encounters. Social workers need to not just understand the world in some overarching sense but because, in its encounters with individuals, it needs a knowledge base that can address the core issues of why people do what they do, and how people might stop doing what they do. 'Why don't (some) people change, when it seems to be in their best interests' is perhaps a classic response of the first placement social work student, grounded either in positivist psychology, or indeed postmodern inflected sociology which ascribes a great deal of agency to individuals (Ferguson, 2001).

The questions of: 'How is it that this woman who is clearly being abused by her partner cannot bring herself to leave, or indeed has left several times, but returns? Or how has she found/been found by, another partner so similar to the last that she is still abused?' are illustrative. A sound political argument in relation to patriarchal oppression, focussing on power and its material manifestations: benefits, housing, jobs with equal pay, child care etc. has been generated over nearly half a century now. The refuge movement has grown alongside these important understandings, and many women have been supported to leave their abusers. But many have not left, and some have returned, and numbers of men go on with their violence. This, like many 'refusals' of agency, can be easily interpreted as a failure, or as indicative of 'weakness', or a lack of motivation, or pathologised as something near addiction to violence or violent men. A derogatory account of the women who stay, and even more so if in staying they 'fail to protect their children', is generated through such ideas.

Psychosocial thinking here offers a different account of not exercising agency, which still locates the actors within relations of structural power, but also seeks to understand their subjectivity, rather than cast them as helpless victims, evil perpetrators and/or the weak-willed. Hoggett's seminal paper on 'Agency, Rationality and Social Policy' (2001) is still of enormous use in challenging the 'agency versus determinism' impasse as illustrated by 'going or staying', 'acting or remaining passive' dilemmas, such as the one above, which social workers regularly confront. This suggests that people's agency is neither freely available to be drawn on as a rational tool for personal change or action at will, nor is it similarly (wilfully) switched off. Reflection is part of agency in many situations, as adopted ('I made a decision to . . $\therefore$; ‘. ... after

Taylor and Francis Not for distribution Liz Frost 120 
thinking hard about it, I choose to...'), and not, ('I just did it on the spur of the moment'; 'I didn't think, I just acted...'). This analysis does not position agency as the preferable state, even though this seems to have been the tone of much writing about agency, and indeed the zeitgeist of the twentieth and twenty-first century, particularly the neoliberal state: 'just do it'; take control; you can make your life better; dependency is a failure. The implication here though, is that agency is not prescriptive or privileged. It is not better per se than non-agency. Violently lashing out at someone may be a demonstration of agency, but the individual may have been unable to draw on reflection: in other words, cannot/does not think about it. Women who stay with violent men may have the capacity to reflect on their situation. Not assuming agency is not the same as nothing (Hoggett, 2001; Frost, 2008).

Even more importantly than the understanding that agency and reflection are both constituent parts of humans, is the psychosocial argument that the inner world of the person also impacts on agency: on whether and how they can act. The internal landscapes of people are not rational and ordered, but anxious, ambivalent, desiring, hating, and so on. Acting in one's own interests then, can be thwarted by contradictory needs and desires, which might be recognised, partially recognised, or not recognised. Fears of abandonment, of loss of love, of dependence, guilt and vulnerability: many emotions that people often cannot easily access, face or examine, may be part of why women stay (and also part of why men abuse). Where social workers consider that service users are 'not trying to help themselves', internal conflicts, not lack of will-power, may be a more useful place to begin to understand the depth and complexity of people's struggles alongside their material struggles.

These are the kinds of ideas that the psychosocial-oriented curriculum encourages social work students to consider. However, what it also attempts to address, in education and in practice, and at the boundaries of these two modes, is the situation of the self in the social work encounter. Education in social work has, like psychosocial theory itself, multiple dimensions and blurred boundaries. Reflection, for example, is frequently on the curriculum: learning about oneself and crossing the mistakenly labelled 'division' between experiential, practice, and theoretical learning is usually seen as a necessary concomitant to social work practice, and certainly of fundamental importance in relationship-based practice (Ruch et al., 2010).

That self-knowledge - all our 'knowledge', including both how and what one understands - can only be mediated through one's personal subjectivity is also a fundamental tenet of psychosocial scholarship. The whole learning process is highly personal but also comprehensible psychosocially. A significant proportion of my social work students come from 'non-standard' backgrounds. They may come from families with little 'book learning' and/or communities where these skills are not necessarily highly valued. Additionally, they may have had experience of an education system failing to support their struggles, and defensively transferring that failure onto the individual, as the label 'school refuser' encapsulates. In tutorial situations, or when we discuss an assignment, it is clear that often they cannot 'look' at their work, because what they see - what they think they see - is 'rubbish'; 'a bit shit', and frequently 'it's no good' is extended to 'I'm no good' in an emotionally driven process of self-laceration and a punitive lack of confidence. Social structural damage, converted to shame, renders the business of education very painful. Particular biographies, in which experiences of denigration within social structures, and/or early psychic development, make self-confidence hard to achieve.

Where these kinds of issues of 'knowledge' overlap with 'self-reflection' such experiences can also however be a working tool for social workers. They render having a greater understanding of the position of some service users far more likely. This is a psychosocial researcher (in gender and class identities) discussing how self-knowledge - of class envy - informed her (their: the research team's) construction of knowledge:

Taylor and Francis Not for distribution Why psychosocial thinking is critical 121 
Our class background has remained a central issue in this part [data analysis] of the study ... For example some of the middle class girls initially evoked our envy ... Using our own subjectivity and experience of being envied by members of our families was part of the process of understanding envy in a more useful way and being able to use it as a tool with which to examine the psychic aspects of the lives of the middle class girls.

(Walkerdine et al., 2001: 84)

This is important, and in social work, arguably, vital, not least because it can pursue ideas of human struggling across the 'us and them' boundary. It encourages, as does relationship-based practice, workers to draw on their identity to make connections, identify with, form a greater understanding of - as well as generate a more 'rich' grasp of social injustice and the need for equality. And, as the Walkerdine et al. quote demonstrates, understand when their internal worlds occlude the interpretation of other people's. Your anger or theirs? Your defences or theirs? Your despair or theirs? But also: your privilege? Your power? Your well-being?

I will pursue this issue, of 'use of self', or 'commonality', here in relation to the illustrative example of shame, as the experience of many social work service users and many social workers. Shame, understood psychosocially, draws on psychoanalytical and social structural thinking. It exists as a political force and a deeply private feeling. It is isolating, self-persecuting, and seems to lead to withdrawal from social connection, not, as Honneth suggests, political action (1992). Sennett and Cobb (1973) typify shame: seeing class damage as one's own 'fault'.

Psychoanalytically shame can be understood thus: all of us have the potential to feel shamed, but some more so than others. The affective unconscious 'landscape' of the individual is structured in early childhood, and will develop with specific, though not always consistent, propensities to experience the world as benign/persecutory (on a spectrum, not as alternatives). Parent-child relations do not always support a baby internalising a sense of her or himself as lovable: as mattering and 'worth something'. This can be theorised as an attachment issue, but this may narrow the scope of understanding (Walker, 2011). One might more usefully think about this as parental incapacity to prioritise a baby's needs for nurture, attunement, empathy. The outcome is the same: what is reflected back to the baby, and becomes absorbed as their version of self, is a profound lack of self-worth. Hence shame becomes more likely. This suggests shame as a form of damage, where an infant is not nurtured.

However, the object relations author frequently turned to by shame theorists, Donald Winnicott, argues that all individuals have a potential for feeling ashamed. Certainly, he too argued that the relationship between the mother (figure) and her baby at the early stages of infancy was formative (1958). Infants absorb, within their early caring relationship, states of being such as trust, dependence, and so on, and where these are incorporated into their developing psyche, can move from dependence to independence, trust to self-confidence, care to caring, and so on. An infant can internalise the meeting of needs and develop the capacity to meet them from their own psychic resources, where they have been met. Whether an adult can love, nurture, trust, experience a coherent and satisfactory sense of self, and indeed receive love, friendship, caring etc. is shaped by their internal world - their individuated internal landscape, set in motion by early object relations.

Additionally, though, as I have argued elsewhere:

This same phase also lays down the capacity for shame as a universal experience, as the baby's sense of omnipotence is revised in the face of experiences of ordinary limitations, small (but not to a little child) failures, gaps in competence, need of the (m)other and so on. The toddler learns itself to be vulnerable, dependent and frail, not omnipotent: a basis for shame.

(Winnicott, 1958; Frost, 2015)

\section{Taylor and Francis Not for distribution Liz Frost 122}


These painful feelings, this suggests, are part of the ordinary make-up of adults. Present in their dynamic unconscious are dependence, anxiety, imperfection, vulnerability: the kinds of feelings that many of us choose to keep hidden, because they are the essence of a sense of shame. Shame has those feelings at its root: whether disguised or open, whether service user or social worker. Not 'us and them' but everyone.

However, crucially for a psychosocial 'reading' of shame, are also the politically and socially generated dimensions of shame that interface with this psychic world, causing maximum damage. Poverty, particularly, as an outcome of political decisions, and in a context of unassailable western materialism, generates social discourses of denigration, disrespect and blaming, which are then internalised by those designated thus (Chase and Walker, 2012).

Austerity policies impact on mental health, and 'humiliation and shame' are at the top of this list, argue groups such as Psychologists Against Austerity (McGrath et al., 2015). Inequality connects to crime, and violence can then be understood as an attempt to re-instigate the respect which has been shattered by being cast as less than respect-worthy (Wilkinson and Pickett, 2009). Health (morbidity and mortality) connects to inequalities (Marmot et al., 2010) and an analysis of this as an issue of respect and worth, as well as material distribution, or rather inseparable from material distribution, is emerging. Complicated social states such as loneliness also connect to shame. Chase and Walker discovered the intensity of this in their poverty research:

There were numerous occasions where interviewees variably described avoiding social situations which risked exposing their lack of resources; pretending that they were coping better than they were; making out they were working when they were in receipt of benefits; and not admitting to needing help because it would mean a loss of pride or face. Such responses led to temporary withdrawal, hiding or pretense at one end of the spectrum, to attempted suicide and permanent social withdrawal at the other, ultimately demonstrating the potential of povertyrelated shame to eliminate those who feel unable to measure up to the normative expectations of society.

Shame, then, is unarguably a core issue in social work: at the heart of much interaction with service users (even to be visited by a social worker is a source of shame for many), and also of relevance to understanding the profession. Gibson's $(2016,2014)$ work on social workers and shame is relevant here. The ongoing damage from consistently negative media coverage, and hence being part of a denigrated profession, is one important aspect. But shame is also generated by the personalised sense of failure to achieve dreams of bringing about social justice and/or situational improvement for service users, for some workers the very reason they entered the profession. There are also the feelings of helplessness and alienation connected to burnout; and the relative powerlessness within the structures of 'welfare' (e.g. in the face of medical, judicial and economic constraints) giving social workers experiences of shame, which will also intermingle with their own autobiographical affective and social landscapes. Shame may have some dimensions of shared experiences of denigration, though it is important to keep in mind that these are differentially generated. I am not equating grinding poverty with poor press coverage, and neither should social workers. However, the emotion generated - the experience of feeling shamed and ashamed - does transverse 'them and us', and introduce mutuality: a starting place for social workers to really get to grips with what this is like for service users, and also to offer clues as to what it produces, and prevents.

Whether one makes the point sociologically (Scheff, 2014), psychoanalytically (Lynd, 1958) or philosophically (Nussbaum, 2004) it seems clear that shame 'disconnects' people. It alienates,

Taylor and Francis Not for distribution Why psychosocial thinking is critical 123 
represses and silences, making people retreat and withdraw from communities of all kinds. Therefore, to practice with the shamed individual (or community or organisation), has as a necessary starting point, both surfacing and acknowledging shame: of building bridges for communication within relationships which counterbalance shame with recognition and caring. Even self-blame can sometimes be reduced by being able to understand more about what and who generates shame. 'It's not your fault' can sometimes be heard and taken in.

As the above implies, 'use of self', now incorporated into notions of reflexive practice and relationship-based practice, is at the heart of social work relationships which can surface and detoxify potent and crippling emotions such as shame. Relationship-based practice, formulated by, for example, Trevithick more than a decade ago, built psychosocial principles into the heart of its method. For example, she discusses both the impact of social exclusion and poverty on service users, as well as defence mechanisms and despair (2003). Ruch et al. (2010) continue to develop this, aligning an understanding of 'the commodification of the individual', with theories which explain transference, anxiety and defences as both individual and organisational phenomena. 'Use of self' continues to be foregrounded: the human subject is at the centre of understanding (Froggett et al., 2015).

This seems a good note on which to conclude. The chapter has argued that psychosocial thinking is critical for and in social work, in both the sense of necessary and in the sense of offering a critique of existing theory and practices. It has suggested that, even given some terminological blurring, it offers a rigorous, useful and deeply applicable form of social science analysis for working with struggling subjects in oppressive social contexts. It also considers the strengths of psychosocial thinking for reflexive 'use of self' in the service-user-social-worker relationship. As Froggett et al. agree:

our students need critical contextual awareness and understanding of inter-subjective relations at the practice interface.

Psychosocial thinking provides exactly this: critically.

\section{References}

Bourdieu, P. (1973). Cultural reproduction and social reproduction. In R. Brown (ed.), Knowledge, Education and Social Change. London: Tavistock.

Bourdieu, P. (1999). The Weight of the World: Social Suffering in Contemporary Society. Cambridge: Polity Press.

Briggs, S. (2008). Working with the risk of suicide in young people. Journal of Social Work Practice: Psychotherapeutic Approaches in Health, Welfare and the Community, 16(2): 135-148.

Brown, S. \& Stenner, P. (2009). Psychology without Foundations. London: Sage.

Chase, E. \& Walker, R. (2012). The co-construction of shame in the context of poverty: Beyond a threat to the social bond. Sociology, 47(4): 739-754.

Clarke, S. (2005). From Enlightenment to Risk, Social Theory and Contemporary Society. Basingstoke: Palgrave Macmillan.

Cooper, A. \& Lousada, J. (2005). Borderline Welfare: Feeling and Fear of Feeling in Modern Welfare. London: Karnac.

De Beauvoir, S. (1970). The Coming of Age. London: W.W. Norton \& Co.

Feiring, S. and Taska, L. (2005). The persistence of shame following sexual abuse: A longitudinal look at risk and recovery. Child Maltreatment, 10(4): 337-349.

Ferguson, H. (2001). Social work, individualization and life politics. British Journal of Social Work, 31(1): 41-55.

Taylor and Francis Not for distribution Liz Frost 124 
Ferguson, H. (2005). Working with violence, the emotions and the psycho-social dynamics of child protection: Reflections on the Victoria Climbie case. Social Work Education, 24(7): 781-795.

Foucault, M. (1977). Discipline and Punish. Harmondsworth: Penguin.

Froggett, L. (2002). Love, Hate and Welfare: Psychosocial Approaches to Policy and Practice. Bristol: The Policy Press.

Froggett, L., Ramvi, E. \& Davies, L. (2015). Thinking from experience in psychosocial practice: Reclaiming 'use of self'. Journal of Social Work Practice: Psychotherapeutic Approaches in Health, Welfare and Community, 29(2): 135-150.

Frosh, S. (2012). A Brief Introduction to Psychoanalytical Theory. London: Palgrave Macmillan.

Frosh, S. (2014). Debates from studies in the psychosocial. Journal of Psychosocial Studies, 8(1): 159-169.

Frost, L. (2008). Why teach social work students psychosocial studies? Social Work Education, 27(3): 243-261.

Frost, L. (2016). Exploring the concepts of recognition and shame for social work. Journal of Social Work Practice: Psychotherapeutic Approaches in Health, Welfare and the Community, 30(4): 431-446.

Frost, E. (2015). Why social work and sociology need psychosocial theory. Nordic Social Work Research, 5(1): 85-89.

Frost, L. \& Hoggett, P. (2008). Human agency and social suffering. Critical Social Policy, 28(4): 438-460.

Gadd, D. \& Dixon, B. (2010). Losing the Race: Thinking Psychosocially about Racially Motivated Crime. London: Karnac.

Gibson, M. (2014). Social worker shame in child and family social work: Inadequacy, Failure and the struggle to practice humanely. Journal of Social Work Practice, 28(4): 417-431.

Gibson, M. (2016). Social worker shame: A scoping review. British Journal of Social Work, 46(2): 549-565.

Giddens, A. (1984). The Constitution of Society: Outline of the Theory of Structuration. Cambridge: Polity Press.

Goffman I. (1959). The Presentation of Self in Everyday Life. Harmondsworth: Penguin.

Hadar, U. (2013). Psychoanalysis and Social Involvement: Interpretation and Social Action. 'Studies in The Psychosocial' Series. Basingstoke: Palgrave Macmillan.

Hoggett, P. (2001). Agency, rationality and social policy. Journal of Social Policy, 30 (1): 37-56.

Hoggett, P. (2014). Learning from three practices. Journal of Psychosocial Studies, 8(1): 179-196.

Hoggett, P., Wilkinson, H. \& Beedell, P. (2013). Fairness and the politics of resentment. Journal of Social Policy, 42(3): 547-565.

Hollway, W. \& Jefferson, T. (2012). Doing Qualitative Research Differently: A Psychosocial Approach. London: Sage.

Honneth, A. (1992). Integrity and disrespect: Principles of a conception of morality based on the theory of recognition. Political Theory, 20(2): 187-201.

Houston, S. (2010). Beyond Homo Economicus: Recognition, self-realisation and social work. British Journal of Social Work, 40 (3): $841-857$.

Houston, S. (2016). Empowering the 'shamed' self: Recognition and critical social work, Journal of Social Work, 16(1): 3-21.

Jimenez, L. \& Walkerdine, V. (2011). A psychosocial approach to shame, embarrassment and melancholia amongst unemployed young men and their fathers. Gender and Education, 23(2): 185-199.

Lynd, H. (1958). On Shame and the Search for Identity. New York: Harcourt Brace.

McGrath, L., Griffin, V. \& Mundy, E. (2015). The Psychological Impact of Austerity: A Briefing Paper. Retrieved from: http://www.workstress.net/sites/default/files/2015Conference_psychological-costs-of-austerity-briefing-paper-compressed.pdf [Accessed 01 Oct. 2018]

Marmot, M., Allen, J. \& Goldblatt, P. (2010). Fair Society, Healthy Lives: Strategic Review of Health Inequalities in England Post2010. (The Marmot Review). London: Department of Health.

Nussbaum, M. (2004). Hiding from Humanity: Disgust, Shame and the Law. Princetown, NJ: Princetown University Press.

Payne, M. (2015). Modern Social Work Theory. Oxford: Oxford University Press.

Pease, B. \& Fook, J. (eds) (1999) Transforming Social Work Practice: Postmodern Critical Perspectives. London: Routledge.

Ruch, G., Turney, D. \& Ward, A. (2010). Relationship-based Social Work. London: Jessica Kingsley Publishers.

Rutter, M. L. (1999). Psychosocial adversity and child psychopathology. The British Journal of Psychiatry, 174: 480-493.

Scanlon, C. \& Adlam, J. (2013). Reflexive violence. Psychoanalysis, Culture \& Society, 18(3): 223-241.

Scheff, T. (2014). The ubiquity of hidden shame in modernity. Cultural Sociology, 8(2): 129-141.

Taylor and Francis Not for distribution Why psychosocial thinking is critical 125 
Sennett, R. \& Cobb, J. (1973). The Hidden Injuries of Class. New York: Vintage Books.

Trevithick, P. (2003). Effective relationship-based practice: A theoretical explanation. Journal of Social Work Practice, 17(2), 163176.

Walker, J. (2011). The relevance of shame in child protection work. Journal of Social Work Practice, 25(4), 451-463.

Walkerdine, V., Lucey, H., \& June, M. (2001). Growing Up Girl: Psycho-Social Explorations of Gender and Class. London: Palgrave Macmillan.

Walkerdine, V. (2014). Felix Guattari and the psychosocial imagination. Journal of Psychosocial Studies, 8(1): 146-158.

Wilkinson, R. \& Picket, K. (2009). The Spirit Level: Why Equality is Better for Everyone. Harmondsworth: Penguin.

Winnicott, D. (1958). The Maturational Process and the Facilitating Environment: Studies in the Theory of Emotional Development. London: The Hogarth Press.

\section{Taylor and}

